\title{
Jurandir Freire Costa
}

Recebido em: 03/08/2014

A entrevista escolhida para esta seção temática sobre Psiquiatria é um retorno aos tempos iniciais do Instituto de Medicina Social, e também por isso, uma forma de reconstituir, por meio dela, um pouco da memória do Programa de Pós-graduação em Saúde Coletiva em seus 40 anos, completados em 2014.

O entrevistado, Jurandir Freire Costa, psiquiatria, psicanalista, professor da UERJ, pensador da cultura e figura de marcada importância na formação do campo "psi" (psiquiatria, psicologia e psicanálise), vem sendo lido e ouvido por muitos, de diferentes gerações e profissōes diversas nas últimas décadas. No campo da saúde mental, dificilmente suas obras não são de leitura obrigatória. Sua militância por uma saúde mental não normativa e seus posicionamentos e comentários sobre a cultura publicados em veículos de massa têm tido enorme influência no debate nacional de ideias. Em 1974, logo depois de voltar de um período de estudos da França, Jurandir entrou para o Departamento de Psiquiatria da UERJ, e pouco depois para o recém-inaugurado Instituto de Medicina Social.

O entrevistador, Benilton Bezerra Jr., psiquiatria, psicanalista, também professor da UERJ, formou-se numa das primeiras turmas de residência em Psiquiatria da UERJ, tendo em seguida ingressado na pós-graduação do IMS sob orientação de seu entrevistado.

Desde então, as trajetórias de ambos vêm compartilhando interesses relações entre psicanálise e cultura, psicopatologia, teoria da clínica, genealogia e epistemologia do campo psiquiátrico, filosofia da mente, história das formaçōes subjetivas. Para além disso, entrevistado e entrevistador participaram da Reforma Psiquiátrica brasileira desde seus primeiros passos e durante anos atuaram juntos em dispositivos da rede de atenção psicossocial, como o Centro Psiquiátrico Pedro II (hoje IMAS Nise da Silveira) e o Hospital Philippe Pinel, no Rio de Janeiro. 
A força desse encontro ainda se faz visível na vitalidade que se pode reconhecer nas aulas, palestras e nas obras de ambos, nas quais se observa uma clara recusa às zonas de conforto ou de conformismo profissional, e o comprometimento com a ação de pensar, repensar e recriar a Psiquiatria naquilo que ela comporta de dinâmico e inquietante.

Esta entrevista é, em um só tempo, uma homenagem a Jurandir Freire Costa, recentemente aposentado do Instituto, mas ativamente presente em suas atividades, um elogio ao trabalho em comum que Jurandir Freire Costa e Benilton Bezerra Jr. realizaram e realizam, dissipando e recebendo ideias em suas atividades de pesquisa, estudo e clínica; e por fim, uma forma de refrescar a memória e abrir horizontes para o porvir do campo "psi", num momento de particular importância e maturidade do Instituto de Medicina Social.

Benilton Bezerra Jr: Tendo em vista o fato de você ter testemunhado a trajetória da psiquiatria brasileira nesses últimos 40 anos de prática profissional, faça um breve panorama desse cenário.

Jurandir Freire Costa: A reforma psiquiátrica no Brasil começou no final dos anos 1970, nutrindo-se da forte atmosfera de inquietação política e de mobilização social da época. A luta "por uma sociedade sem manicômios" era, na consciência de seus militantes (e a maioria dos profissionais de saúde mental era, de fato militante), a expressão localizada de um engajamento mais amplo por uma sociedade melhor - mais justa, mais tolerante, mais eficaz no cuidado com os mais frágeis e na defesa da autonomia do sujeito. A percepção da dupla natureza - clínica e política, científica e moral - inerente à prática psiquiátrica era algo natural para geraçôes que liam Basaglia, Foucault, Castel, Guattari, aprendiam psicopatologia com Jaspers e Henry Ey. Passados mais de 30 anos, isso mudou. A ação política perdeu seu poder de atração; as consignas e as experiências localizadas se transformaram em programas de governo; o entusiasmo político foi sendo triturado pelo monstro da administração burocrática; a psiquiatria biológica tornou-se hegemônica, embalada pelo prestígio da neurobiologia na cultura; a vulgarização do vocabulário psiquiátrico abriu espaço para uma psiquiatrização, em escala inédita, da infância e da vida cotidiana. Para muitos, a força instituinte inicial da reforma mostra sinais evidentes de esgotamento. 
Benilton Bezerra Jr: Vocêparticipou de uma das primeiras experiências da reforma, no Centro Psiquiátrico Pedro II, no Rio de Janeiro (atual IMAS Nise da Silveira). Quais as lembranças mais marcantes desse periodo, e como você vê o cenário da psiquiatria brasileira atual?

Jurandir Freire Costa: As lembranças mais marcantes são as que você acabou de evocar. Não existe saber psiquiátrico independente de contexto. A psiquiatria contemporânea reflete as ideias que temos da natureza e finalidade dos saberes narrativo-científicos e das imagens ideais de nós mesmos. Fazemos psiquiatria confiando a priori na excelência das grades analíticas que usamos e de olho naquilo que são nossos ideais de eu. Em suma, recorrendo à simples e eficiente fórmula criada por Rorty, diria que há saberes que visam "controlar e predizer o comportamento do sujeito estudado" e outros que sugerem "como fazer para viver melhor", qualquer que seja o sentido que venhamos a dar à expressão "viver melhor". Penso que não há como driblar a sombra normativa dessas molduras. Se hoje as chamadas "neurociências e neurobiologias" fascinam nossas mentalidades, é por espelharem o horizonte cultural que ambiciona "neutralizar moralmente" as penosas experiências que temos diante do sofrimento humano. Neutralizar, aqui, tem o sentido de diminuir o fardo das decisões morais num universo individualista, atomizado, social e economicamente inseguro e dominado pela "dessublimação repressiva", como disse Marcuse, ou pelo imperativo superegoico do gozar, como prefere Žižek. Fique claro, não nego os avanços científicos nestas áreas, apenas reafirmo o que Althusser disse certa vez: entre a prática científica e a ideologia espontânea dos cientistas "il n'ya qu'un pas", para repetir a boutade freudiana. E, como no exemplo original de Freud, "o passo" em questão pode ser algo completamente tolo e irrelevante ou absurdamente paralisante para a investigação da vida mental.

No que concerne à psiquiatrização da vida cotidiana, continuo a pensar na chave foucaultiana: a psiquiatria nasceu comprometida com a medicalização das vidas nuas ou corpo dóceis. Hoje, certamente, a psiquiatrização é diferente do que foi. Mas continuamos a exportar para a cultura leiga categorias teóricas responsáveis pela produção de novos modos de subjetivação, e a receber em troca a "confirmação" ou a "evidência" de que o que pensamos é correto. O efeito "looping” estudado por Ian Hacking talvez seja mais explícito agora. Em minha 
opinião, contudo, esse efeito sempre existiu desde o nascimento da psiquiatria. Infelizmente, não poderia dizer grande coisa sobre o andamento da "Reforma". Estou afastado da prática e não conheço o que vem sendo elaborado teoricamente sobre a experiência, pois passei a me dedicar a outros problemas.

Benilton BezerraJr: A Reforma no Brasilapresenta caracteristicasmuitoparticulares, em comparação com o que ocorreu em outros paises. Uma dessas peculiaridades foi a forte presença de psicanalistas no movimento, desde seu inicio, que levou a dimensão psicodinâmica da clínica a ter importância considerável nos experimentos brasileiros, como foi o caso do primeiro CAPS, liderado por Jairo Goldberg, em São Paulo. Essa presença no sistema assistencial brasileiro não deixou de provocar tensões. No início, elas apareciam nos debates que opunham "clinicos" e "politicos". Recentemente, têm aparecido em críticas feitas por profissionais de outras orientaçôes teórico-clínicas, que se queixam do que consideram pretensöes hegemônicas dos psicanalistas nos serviços. Como psicanalista e psiquiatra que atuou como clínico, professor, supervisor de várias geraçôes, como você avalia essa característica da reforma brasileira?

Jurandir Freire Costa: Esse é um problema difícil de abordar. Não poderia afirmar algo sobre o assunto que ajudasse a relançar de forma produtiva a discussão. Seja como for, penso que nos anos 1970-1980, psicanalistas, psiquiatras e outros trabalhadores de saúde mental comprometidos com a reforma conseguiram obter um consenso mínimo sobre o valor das "micropolíticas" de resistência ao regime ditatorial. Era como se a rivalidade decorrente do narcisismo das pequenas diferenças psiquiátrico-psicanalíticas tivesse vivido, de forma implícita, uma trégua tática. A violência da ditadura era o inimigo maior, e a luta pela humanização dos manicômios, pela despsiquiatrização das vidas e pelos experimentos culturais informados pelos pensadores pós-estruturalistas, sobretudo os franceses, parecia a resposta possível e desejável à opressão. Em seguida, vieram os tempos das injustiças sociais pacificadas e retomamos as repetitivas e cansativas guerras por rodapés de doutrinas. Há algo, entretanto, que julgo muito interessante. Seria enriquecedor se pudéssemos fazer um estudo do tipo psiquiatria transcultural sobre a grande participação de psicanalistas em serviços públicos concebidos por Basaglia, um notório adversário teórico da psicanálise. Isso, acredito, seria um estudo transcultural realmente interessante, pois se trata de um fato de ponta a ponta "brasileiro". Uma investigação do gênero talvez trouxesse de volta à cena 
intelectual a questão da enorme difusão da psicanálise no Brasil, comparada com o relativo desinvestimento cultural desse saber em outros países europeus, para não citar os Estados Unidos, onde a prática é residual, em relação ao "boom" dos anos 1950 até início dos anos 1980. Lembro-me de um artigo do Luciano Martins, A geração AI-5, que procurou entender o sentido deste apetite brasileiro por psicanálise. Ao que saiba, nada se fez de muito significativo posteriormente. Acho, portanto, que analisar de modo cuidadoso por que a psicanálise teve e tem uma importância de monta em práticas psiquiátricas inspiradas por Basaglia seria algo de fato brasileiramente "transcultural".

Benilton Bezerra Jr: O historiador Edward Shorter escreveu que "a série do DSM é mais um documento cultural do que cientifico". Isso significa, de um lado, que suas várias versóes refletem, no discurso psiquiátrico, conceitos e valores presentes no imaginário cultural; de outro, que a infiltração de seu vocabulário na linguagem ordinária produz efeitos prescritivos sobre a subjetividade. Diagnósticos psiquiátricos têm participado de maneira crescente nos processos de construção identitária. Esse é um processo de significação complexa, que não se deixa elucidar por análises simplistas. Se é verdade que a vulgarização das categorias psiquiátricas leva a uma medicalização abusiva de comportamentos e experiências inerentes à vida cotidiana, é fato que nem sempre o diagnóstico implica estigma, controle e exclusão, como a produção de narrativas autobiográficas por autistas deixa bem claro. Como você vê esse fenômeno? Jurandir Freire Costa: Como disse, penso que qualquer prática ou teoria psiquiátrica é um "documento cultural”, como diz Shorter. O que existe atualmente é uma maior consciência crítica por parte dos leigos quanto ao impacto dos diagnósticos médicos em suas vidas. A complexidade cultural fez com que o diagnóstico psiquiátrico, antes predominantemente excludente, agora fosse reapropriado de forma a beneficiar os sujeitos anteriormente prejudicados com a rotulação estigmatizante. Desse aspecto, até os diagnósticos de teor biologizante, cerebralizante ou neurologizante passaram a ser instrumentalizados de maneira positiva. Ou seja, os supostos portadores de deficiências orgânicas passaram a reivindicar a isenção de certas responsabilidades sociomorais ou a obtenção de privilégios sociais - como cotas de preferência em instituições de trabalho e ensino ou outros tipos de assistência social - justificando suas condutas como sendo produto de fatores impessoais ou involuntários. 
A meu ver, parece claro que essa guinada só se tornou possível dado o surgimento, no panorama cultural, das "políticas de minorias identitárias" e da ampliação do campo do direito, que se estendeu da pura esfera dos "direitos civis" para a esfera dos "direitos humanos". As minorias psicológicas se beneficiaram dessa nova sensibilidade política, não sem algumas consequências adversas. Como notou Philip Rieff 50 anos atrás, a hegemonia ideológica do "indivíduo" sobre o "cidadão" produziu uma metamorfose inesperada no imaginário do viver coletivo. Ao mesmo tempo em que nos tornamos superlativamente afetáveis por dores, traumas, sofrimentos e opressões de grupos e indivíduos numericamente minoritários, nos tornamos estranhamente blindados a injustiças e discriminações sofridas por povos e massas de indivíduos social, política e economicamente marginalizados. A equação pode ser um tanto esquemática, mas, sem dúvida, corresponde à abulia política contemporânea, acuada entre a incontestável mediocridade - quando não ilegitimidade - dos atuais governos nas democracias liberais e a dificuldade de imaginar saída para esse estado de coisas mediante os projetos libertários dos séculos XIX e XX. Em resumo, o uso de termos psiquiátricos como atributos para a construção de identidades pessoais é uma faca de dois gumes. Pode ser sinal da maior aceitação do convívio com a diversidade humana ou indício de que a lupa no indivíduo pode fazer-nos ficar cegos em face da teratologia da ordem social.

Benilton Bezerra Jr: Um dos fenômenos culturais mais interessantes nas últimas décadas a repercutir no cenário psiquiátrico foi a emergência de movimentos de defesa do direito de livre expressão e de plena cidadania daqueles que falam em nome da diferença. Modalidades de organização subjetiva, de orientação sexual, ou de conformação corporal anteriormente classificadas como anormais ou patológicas cada vez mais reivindicam o estatuto de singularidades atípicas, mas nem por isso menos normativas - como é o caso dos Aspergers que se autoproclamam neurodiversos. Esse fenômeno tem raizes em reformulações recentes dos fundamentos que sustentam a distinção entre normalidade, atipia, e patologia, processo que envolve dimensões epistemológicas ou conceituais, e vetores politico-culturais. Do ponto de vista conceitual, o que lhe parece estar mudando na maneira de ordenar a distinção entre essas categorias? Do ponto de vista histórico-politico, o estabelecimento das fronteiras entre normalidade, atipia e patologia sempre implica um arranjo de forças que 
determina que modalidades de sofrimento são legitimas e aceitáveis, e quais devem ser tratadas, corrigidas ou eliminadas. Isso significa que toda sociedade, mesmo a que se quer tolerante, como a nossa, produzirá seus anormais, aqueles sobre cujo modo de vida recai o furor curandi. Quem são, a seu ver, os anormais de hoje?

Jurandir Freire Costa: A questão é gigantesca e jamais poderia ser respondida no espaço de uma entrevista. Vou me concentrar, portanto, em um dos aspectos: a dimensão epistemológica. Dois fatos me parecem importantes no debate sobre o tema. O primeiro tem origem no interior do corpo teórico produzido pelos especialistas; o segundo, no saber produzido pelos sujeitos que são objeto das classificações, investigaçôes ou práticas terapêuticas científicas. No interior do campo especializado, a polêmica sobre a validade lógica de um termo como "típico" é cada vez mais contestada, desde a biologia evolucionista até o campo da medicina mental, se me permitirem a leniência intelectual com esta última expressão. A norma, digamos de modo abrupto, é a "atipia”, a variação constante, e não a permanência. $\mathrm{O}$ mesmo pode ser dito de antigos termos passe-partout como "funcional" e "disfuncional". Ao perdermos a segurança imaginária que tínhamos no uso e abuso do que pode ser considerado "atípico" e "disfuncional", perdemos a suposta nitidez da linha de corte entre o "psicopatológico" e o "psicológico típico e funcional". Agora, o problema é saber quais critérios empregamos para dividir as diversas formas de vida psicológica entre as que podem se beneficiar do arsenal terapêutico que possuímos e aquelas para as quais tal arsenal seria inútil, inócuo ou nocivo. Não há receita padronizada para resolver o dilema. Tudo depende, em última instância, da cultura científica do pesquisador. Não poderia me estender na explicitação desse tópico. Aos interessados, poderia indicar a tese de Paula Gaudenzi, defendida em nosso departamento no IMS, no início deste ano de 2014. Na tese, as grandes linhas do debate são apresentadas, o que facilita o trabalho dos pesquisadores implicados no assunto.

Passo, então, ao segundo fato acima referido. Trata-se dos depoimentos dos sujeitos diagnosticados como portadores de deficiências psicológicas. Como exemplo, cito o caso do "autismo", seja na vertente da síndrome de Asperger, seja na vertente dos transtornos graves do desenvolvimento. Esses relatos mostram dois aspectos notáveis da mudança do pensamento psiquiátrico nas últimas três ou quatro décadas. O primeiro aspecto é o volume extraordinário de publicações sobre o assunto. Em meu entender, jamais presenciamos na história da psiquiatria 
uma quantidade tão grande de relatos em primeira pessoa, concernentes a casos pretensamente psicopatológicos. A lista é enorme e não para de crescer. Os sujeitos etiquetados de "autistas" não cessam de retificar, criticar ou simplesmente revelar facetas de suas experiências mentais desconhecidas, minimizadas ou sem registro nas teorias dos especialistas.

Como resultado, temos o segundo aspecto mencionado: a verdadeira revolução epistêmica na forma de compreender "atipias" até então involucradas indiscriminadamente numa mesma etiqueta psicopatológica. É uma genuína revisão fenomenológica feita por "leigos" informados - com maior ou menor consistência - por conceitos elaborados por especialistas. Mais, ainda. Os sujeitos não se limitam a impugnar o que foi descrito como atributo psicopatológico de suas experiências mentais. Ao lado disso, trazem à luz modos de organização ou estruturação do funcionamento psicológico pretensamente "normal" ou "típico", ignorados ou desconhecidos no estreito parentesco que possuem com os exemplos "atípicos". Dito de outra forma, a anomalia exibe em tintas fortes o que a forma "nômala" oculta nos hábitos mentais corriqueiros. Todo esse campo de investigação é incipiente, mas acredito que seja extremamente promissor. É nele que aposto, como fonte de inspiração para uma psiquiatria/psicanálise/psicologia mais próxima e mais atenta ao extraordinário colorido da nossa vida mental.

Benilton Bezerra Jr: O DSM-3 foi criado em 1980 como uma resposta ao que era identificado como uma dupla falha do diagnóstico psiquiátrico até então: a precária confiabilidade e a inexistente validade de suas categorias. Com sua perspectiva descritivo-comportamental, o DSM-3 conseguiu resolver o problema mais simples, o da confiabilidade: diagnósticos como o "transtorno explosivo intermitente" ou o "transtorno desafiador de oposição" podem exibir alto grau de confiabilidade, todo mundo diagnostica igual. Mas a validade de diagnósticos como esses continua, para dizer o minimo, polêmica. Eles designam doenças mentais ou são meros rótulos de condutas indesejáveis? Para resolver esse problema, o NIMH (National Institute of Mental Health) americano criou o RDoC, em desenvolvimento desde 2009, que visa construir uma nova nosologia, baseada na pesquisa genética, nos estudos de imageamento e nas ciências cognitivas. Seu objetivo é fundar as categorias psiquiátricas não mais em consensos provisórios acerca de sinais e sintomas, mas em marcadores biológicos e medidas cognitivas. A decisão de que pesquisas sobre 
psicopatologia deixem de lado o DSM e a intenção de conhecer melhor os substratos

genéticos e neurológicos da vida subjetiva podem parecer promissoras. No entanto, a premissa explícita do RDoC é a de que "os transtornos mentais são transtornos biológicos". Como ninguém mais supõe que haja fato subjetivo sem fato biológico, fica a suspeita de que o postulado implique um reducionismo não apenas metodológico. Que expectativas você tem em relação a essa proposta?

Jurandir Freire Costa: Concordo com você. Atualmente, qualquer distinção entre fato biológico e fato mental é simplista e anacrônica. No momento em que funções corporais são transferidas e executadas por suportes físicos não orgânicos; no momento em que parte de nossa memória está em computadores; no momento em que a noção de tempo neutro e linear, como diria Bergson, é cada vez mais confrontada à experiência do tempo como duração e simultaneidade de eventos. Pois bem, nesse momento, afirmar que "transtornos mentais são biológicos e não psicológicos" ou vice-versa soa como uma espécie de defesa da bílis como causa dos distúrbios do humor ou do costume de dançar valsa como causa de sintomas histéricos. O que parece risível, hoje, já foi apresentado como ciência irrefutável, empiricamente provada e teoricamente irrepreensível.

Benilton Bezerra Jr: Um dos processos mais surpreendentes e promissores das últimas décadas no cenário intelectual tem sido o progressivo desmantelamento da antiga divisão que opunha o biológico ao social, o natural ao cultural, propiciado pelas descobertas da biologia contemporânea, em especial os estudos sobre a neuroplasticidade e os fenômenos epigenéticos. Esses estudos vêm delineando uma perspectiva contextualista e dinâmica para a biologia. Nesse sentido, o horizonte atual difere em muito daquele vigente nos anos 1970/80, em que biologia e psicologia, ciências da vida e ciências humanas repartiam seus campos opondo determinismo do corpo e autonomia do sujeito, causas orgânicas e razôes psíquicas, etc. O impacto dessas mudanças é igualmente desafiador tanto para as ciências da vida quanto para as ciências do espírito. Curiosamente, porém, no cenário psiquiátrico parece haver certo atraso na percepção dessa realidade. Deveríamos estar nos perguntando com mais afinco acerca de como repensar questóes como a presença da experiência direta do corpo agindo no ambiente no processo de constituição e regulação da vida psíquica, ou como redescrever o modo como padróes culturais de atribuição de significados acerca do sofrimento (narrativas, práticas discursivas) incidem sobre o funcionamento 

profissionais "psi" ainda se divide entre os bioentusiastas e os biocéticos, se podemos dizer assim. Qual é a sua visão sobre os possiveis impactos na psiquiatria dessa porosidade crescente entre funcionamento biológico e contexto social?

Jurandir Freire Costa: Acho que a resposta a tua questão exigiria uma digressão filosófica, antropológica, histórica, psicanalítica etc., que excederia, em muito, minha limitada capacidade de análise. Apesar disso, vou arriscar duas opiniōes: uma de ordem filosófica e outra de ordem da antropologia psicológica. Do ponto de vista filosófico, penso que o motivo da insistência nesse venerando cacoete teórico é o hábito idealista de querer explicar o complexo pelo simples; o transcendente pelo imanente, em síntese, a angústia de querer encontrar, custe o que custe, um "nómeno" que esgote exaustivamente a causa e natureza do "fenômeno". Materializar a causa do mental significa predizer e controlar as manifestações do substrato do que, pretensamente, seríamos feitos. Um sonho compreensível, mas, mesmo assim, não deixa de ser uma realização mágica do desejo. Contra essa convicção tenaz não há antídoto. Como dizia Rorty, procurar fundamentar racionalmente crenças ou desejos afetivos é procurar secar o mar com uma peneira. O que posso dizer sobre isso é que minhas bússolas intelectuais são outras.

Quanto à antropologia psicológica, acho que os insights de Irving Hallowell são imaginativos e podem oferecer um bom ponto de partida para entender este gênero de querela. Hallowell diz que não conhecemos culturas nas quais a relação com o sentido de realidade socialmente partilhado não se veja duplicado por outra dimensão imaterial, que pode ou não ser interpretada como sobrenatural, espiritual, religiosa etc. O materialismo vulgar do século XIX tentou desesperadamente combater essa realidade cultural por meio de hipóteses toscas sobre a matriz biológica ou psicológica de tais crenças. O objetivo era liberar os sujeitos da "alienação" político-religiosa que os aprisionava, alienação responsável pela miséria econômica da qual padeciam. No fundo, aqueles intelectuais acreditavam que a infância racional da humanidade estava com os dias contados. Enfim, chegara o instante do triunfo da Razão. Hoje, não se trata mais do mito da Razão, mas do mito do progresso da ciência e da tecnologia. No entanto, se você observar com cuidado as teses sobre a gênese e a causalidade biológicas da vida mental - no reducionismo caricato, é óbvio - verá que quase todo vocabulário 
metafísico relativo ao "sujeito" como entidade à parte do organismo físico está presente, ativo e dissimulado num linguajar supostamente livre de superstições psicológicas: representação; decisão; autorreferência; transparência ou opacidade fenomênica; ilusão; intencionalidade; finalidade etc., sem contar os pressupostos do "corpo", do "mundo", da "relação com os outros" e assim por diante. A pergunta é: que circuito, assembleia ou plasticidade neural exaure lógica ou empiricamente a compreensão de todos esses termos "experienciais" sobre os quais se assenta o bioentusiasmo dos partidários das teorias da causalidade neural dos fatos mentais? Para empregar teus neologismos, não me vejo nem como bioentusiasta nem como biocético porque também nem sou psicoentusiasta nem psicocético. Continuo freudiano: hipóteses metapsicológicas são feiticeiras que invocamos para resolver transtornos de mobilidade conceitual diante de engarrafamentos clínicos. Desobstruído o trânsito, aposentamos vassouras e feiticeiras e... vamos ao trabalho! Até que novas feiticeiras se tornem necessárias. 